Proceedings

\title{
Intraspecific Competition Among the Larvae of Habrobracon hebetor on Ephestia kehniella ${ }^{\dagger}$
}

\author{
Taiebeh Sadat Mahdavi ${ }^{1}$ and Hossein Madadi 2,*
}

Citation: Mahdavi, T.S.; Madadi, $\mathrm{H}$ Intraspecific Competition Among the Larvae of Habrobracon hebetor on Ephestia kehniella, in Proceedings of the 1st International Electronic Conference on Entomology, 1-15 July 2021, MDPI: Basel, Switzerland, doi:10.3390/IECE-10571

Published: 2 July 2021

Publisher's Note: MDPI stays neutral with regard to jurisdictional claims in published maps and institutional affiliations.

Copyright: (C) 2021 by the authors. Submitted for possible open access publication under the terms and conditions of the Creative Commons Attribution (CC BY) license (http://creativecommons.org/licenses /by/4.0/).
1 Ph.D. student of Agricultural Entomology, Department of Plant Protection, Faculty of Agriculture, Bu-Ali Sina University: tsmahdavi14@gmail.com

2 Associate Professor of Agricultural Entomology, Department of Plant Protection, Faculty of Agriculture, BuAli Sina University: $\underline{\text { hmadadi@basu.ac.ir }}$

* Correspondence: hmadadi@basu.ac.ir

† Presented at the 1st International Electronic Conference on Entomology (IECE 2021), 1-15 July 2021; Available online: https://iece.sciforum.net/.

\begin{abstract}
Competition defined as an interaction between individuals due to a shared requirement for a common resource. In this study, the experimental unit consisted one five instar larva of Ephestia kuehniella bearing 12 Habrobracon hebetor eggs, which was replicated 25 times. From 25 replicates, in three units only female wasps and from two units only males were emerged. The remained units included male and female wasps together. Male longevity at only male included units was 12.75 \pm 1.5 days, while in two sexed units it was reduced to $9.4 \pm 0.8$ days might be assigned to the competitive pressure of females due to their larger body size and more nutritional needs.
\end{abstract}

Keywords: Intraspecific ompetition; Habrobracon hebetor; Meditteranean flour moth; Fecundity; life history

\section{Introduction}

Some parasitoid wasps have a limited host range, which leads to strong evolutionary interactions between parasitoids and their host [5].

In host-parasitoid interactions, some hosts are attacked by more than one female wasps belonging to the same (superparasitism) or different (multiparasitism) species, a phenomenon that leads to competition between their immatures [13]. In other words, the food might act as a critical factor in the context of competition between individuals of one species or different species or both, and in principle, it is mostly the food factor that causes competition [10] (pp.219-225).

Competition plays an important role in the size, structure and stability of natural enemy communities and sometimes is used in insects as a means of determining fitness [11]. Competition is a relationship or reaction between individuals over a shared need for a resource with limited reserves, leading to reduced survival, growth, or reproduction of competitors. It plays a role in selecting different evolutionary features of parasitoid development, but competition itself is influenced by various factors. One of the most important of these factors is the characteristics of the host such as quality, age, size, density and life stage, as well as environmental conditions such as temperature $[6,8]$. Because access to hosts is of critical importance for parasitoid reproduction, host scarcity may lead to increased intraspecific competition. The negative effects of competition on successful parasitism exhibited as a reduction in adult size and fertility of parasitoids, as well as an increase in host developmental time and therefore host-parasitoid synchrony disruption, and finally waste of searching time for the defeated of this race [7]. 
Given that the Bracon wasp is an idiobiont species that lays its eggs en masse, the hatched larvae are inevitably involved in competition. This study aimed to examine the effect of intraspecific competition of $H$. hebetor larvae on adults longevity.

\section{Materials and Methods}

\subsection{Insect Rearing}

Stock colony of Ephestia kuehniella was initiated by spredaing 0.5 gram of Mediterranean flour moth (MFM) eggs evenly on the surface of a mixture of flour and wheat bran in a ratio of 1: 1 with 3 yeast tablets (laboratoires Vitarmonyl ${ }^{\circledR}$ ). Flour moth colonies have been kept under climate controlled conditions (at $25 \pm 1^{\circ} \mathrm{C}, 60 \pm 10 \%$ relative humidity and 16:8 L:D photoperiod), in ventilated transparent plastic containers $(10 \times 22 \times 27 \mathrm{cms})$.

Adults of $H$. hebetor were collected from chickpea fields (Kermanshah province) and transferred to the laboratory. The wasps were released on fully grown five instar larvae of moth flour (approximately 35 days old) placed in ventilated petri dishes (ca $8 \mathrm{~cm}$ diameter). First, 10 five instar larvae of MFM were placed in each petri and then two pairs of $H$. hebetor wasps were introduced. The wet cotton soaked in pure honey on top surface of the petri dishes was provided to feed the wasps. After 24 hours and ensuring wasp oviposition, the wasps were removed from the petri dish by an aspirator and transferred back to a new container with the same conditions. The larvae carrying wasp eggs were kept in the above described conditions until the adult emergence.

\subsection{Competition Experiments}

After breeding two generations according to the above method, the first cohort was prepared. Then, in each container, one five instar larvae of E. kuehniella (35 days old - from egg to test day-) introduced and then a pair of wasps was released allowed them to lay eggs for 24 hours. Then, except to 12 eggs of $H$. hebetor per E. kuehniella larvae, all remained eggs were removed. After marking the eggs with the fine liner Panter mark, they were transferred to germinator. Marking was performed again after the larvae hatched. All containers were checked daily and hatching of larvae, eggs, larvae and pupae developmental time and survival percentage were recorded. After emergence of all wasp adults, each female coupled with a male and transferred to new dishes. Then, daily spawning rate until the death of the adult was recorded.

From 25 replicates, in three unit only female wasps and from two units only males emerged. The remained units included male and female wasps together.

All experimental units were kept under controlled conditions $\left(25 \pm 1^{\circ} \mathrm{C}, 60 \pm 10 \%\right.$ relative humidity and 16:8 L:D).

\subsection{Data analysis}

Data normality was checked by the Shapiro-Wilk test, and when the normal distribution requirements of parametric distribution were not met, non-parametric tests were used (e.g., the Mann - Whitney U test) and means were compared. In all other cases, T test was used to assess the effects of competition on developmental time and fecundity. For all statistical tests the level of significance was 0.05, and programs were run in Spss 2013.

\section{Results}

The symptoms of host feeding were observed in all experimental units after 24 hours and $H$. hebetor adults fed on host hemolymph. The different developmental time of male in males alone and males and females replicates were compared in Table 1. Accordingly, there was not significant differences in the eggs (Mann - Whitney U-test, $U=608, d f=116$, $\mathrm{P}=0.671$ ), larvae (Mann - Whitney U-test, $\mathrm{U}=458, \mathrm{df}=116, \mathrm{P}=0.09$ ), pupae (Mann - Whitney $\mathrm{U}$-test, $\mathrm{U}=532.5, \mathrm{df}=116, \mathrm{P}=0.341$ ), adults (T-test, $\mathrm{t}=1.783$, $\mathrm{df}=116, \mathrm{P}=0.077$ ) and preadult (Mann - Whitney U-test, $\mathrm{U}=457.5, \mathrm{df}=116, \mathrm{P}=0.106$ ). However, total longevity (T-test, $\mathrm{t}=86.5, \mathrm{df}=116, \mathrm{P}<0.001$ ) and egg-adult duration (T-test, $\mathrm{t}=86.5, \mathrm{df}=116, \mathrm{P}<0.001$ ) were 
significantly different due to competition effect. Accordingly, male longevity at only male included units was $12.75 \pm 1.5$ days, while in two sexed units it was reduced to $9.4 \pm 0.8$ days which might be assigned to the competitive pressure of females (Table 1).

About female wasps, like males, there were significantly difference in the developmental time of eggs (Mann - Whitney U-test, $\mathrm{U}=1130, \mathrm{df}=118, \mathrm{P}=0.56$ ) and larvae (Mann - Whitney U-test, $\mathrm{U}=925, \mathrm{df}=118, \mathrm{P}=0.068$ ). Although, there was a significant difference in the developmental time of pupae (Mann - Whitney U-test, $\mathrm{U}=761, \mathrm{df}=118, \mathrm{P}=0.004$ ) and preadult duration (Mann - Whitney U-test, $\mathrm{U}=781, \mathrm{df}=118, \mathrm{P}=0.007$ ). Moreover, it has been shown that the effect of competition on egg- adult duration of females ( $\mathrm{T}=7.144$, $\mathrm{df}=118, \mathrm{P}<0.001)$ and female total longevity (Mann - Whitney U-test, $\mathrm{U}=781, \mathrm{df}=118$, $\mathrm{P}=0.007$ ) were statistically significant ( $\mathrm{T}$ - test, $\mathrm{t}=6.082, \mathrm{df}=118, \mathrm{P}=0.001$ ) (Table 2 ). This is important because unlike predators, only female wasps help to suppress pest populations.

Fecundity is one of the most important criteria for determining the efficiency of parasitoids. According to Table 2, the fecundity of $H$. hebetor was significantly different across different competition situations ( $T$-test, $\mathrm{t}=3.8, \mathrm{df}=117, \mathrm{P}<0.001$ ).

Table 1. Mean ( \pm SE) developmental time (days) male of Habrobracon hebetor on Ephestia kuehniella across different competitive situations.

\begin{tabular}{ccc}
\hline Parasitoid stages & Male +Female & Only Male \\
\hline Egg & $1.12 \pm 0.3^{\mathrm{a} 1}$ & $1.7 \pm 0.11^{\mathrm{a}}$ \\
Larva & $4.85 \pm 0.07^{\mathrm{a}}$ & $5.25 \pm 0.18^{\mathrm{a}}$ \\
Pupa & $7.44 \pm 0.11^{\mathrm{a}}$ & $7.83 \pm 0.32^{\mathrm{a}}$ \\
Adult & $9.4 \pm 0.8^{\mathrm{a}}$ & $12.75 \pm 1.5^{\mathrm{a}}$ \\
Preadult & $13.41 \pm 0.16^{\mathrm{a}}$ & $14.25 \pm 0.39^{\mathrm{a}}$ \\
Total (egg-adult) & $19.66 \pm 0.87^{\mathrm{a}}$ & $25.19 \pm 0.4^{\mathrm{b}}$ \\
\hline & ${ }^{\mathbf{1}}$ Means within a row followed by different letters are significantly different.
\end{tabular}

Table 2. Mean ( \pm SE) development time (days) female and fecundity of Habrobracon hebetor on Ephestia kuehniella across different competitive situations.

\begin{tabular}{ccc}
\hline Parasitoid stages & Female + Male & Only Female \\
\hline Egg & $1.17 \pm 0.04^{\mathrm{a}}$ & $1.12 \pm 0.06^{\mathrm{a}}$ \\
Larva & $4.84 \pm 0.01^{\mathrm{a}}$ & $5.16 \pm 0.13^{\mathrm{a}}$ \\
Pupa & $8.31 \pm 0.01^{\mathrm{a}}$ & $8.29 \pm 0.14^{\mathrm{a}}$ \\
Adult & $30.24 \pm 0.9^{\mathrm{a}}$ & $18.8 \pm 1.5^{\mathrm{b}}$ \\
Preadult & $14.32 \pm 0.16^{\mathrm{a}}$ & $15.2 \pm 0.23^{\mathrm{b}}$ \\
Total (egg-adult) & $44.56 \pm 0.9^{\mathrm{a}}$ & $31.32 \pm 1.4^{\mathrm{b}}$ \\
Fecundity & $146.12 \pm 7.6^{\mathrm{a}}$ & $34.4 \pm 16.85^{\mathrm{b}}$ \\
\hline & & 1 Means within a row followed by different letters are significantly different.
\end{tabular}

\section{Discussion}

In a competitive condition, when some members of the population die in the early stages of life, the intensity of competition on survivors decreases and they can improve their quantitative and qualitative biological parameters. Furthermore, in females who have a more important role in population increase and pest control, this issue has a greater impact and the process of change is more severe. Female insects need more qualified food than males due to their larger size and oviposition.

The quantity and quality of food eaten by infants affects their activities such as growth rate, life expectancy, body weight, distribution, and survival. Adults suffered from competition, will have less weight and consequently they are less fertile [2] (pp. 8591). Our results showed that competition influenced on male and females differently. It sounds that females does not have negatively affected by competition and in male free replicates the longevity and fecundity decreases substantially. Similarly, competition does 
not increase the developmental time of different life stages of males or reduce male longevity. Collectively, this information could be used for optimizing the mass rearing systems of $H$. hebetor.

\section{Conclusions}

Since access to hosts is vital for successful reproduction in parasitoids, host scarcity may lead to increased intra and inter-specific competition [4]. Competition is a phenomenon that naturally costs for involved individuals, appeared as the decrease in adult size and fertility [3], as well as an increase in developmental time [7]. Moreover it decreases the number of offspring and wastes searching time for the loser [1]. Therefore, as long as non-parasitized hosts are available, they refuse to lay eggs in previously parasitized hosts, a behavior that reduces competition between their offspring. Host discrimination or the ability to distinguish between healthy hosts from parasitized ones is a common phenomenon among parasitoid wasps, and females usually use internal, external, or both to identify pre-parasitic hosts [9]. However, if non-parasitic hosts are not available, spawnings in parasitized hosts can be a form of adaptation and help their survival [12]. Therefore, in order to obtain higher qualified $H$. hebetor wasps, it is better to provide them with enough number of larvae of mediterranean flour moth in the insectarium so that save costs and labor efficiently.

Acknowledgments: Special Thanks to Zoleikha Mirzakhany (PhD student of Agricultural Entomology, Bu-Ali Sina University) for all her valuable assistances provided during the laboratory experiments.

Conflicts of Interest: The authors declare no conflict of interest.

\section{References}

1. Bai, B., Mackauer M. Host discrimination by the aphid parasitoid Aphelinus asychis (Hymenoptera: Aphelinidae): When superparasitism is not adaptive. Can. Entomol. 1990, 122, 363-372.

2. Bandani, A.R. Insect physiology (Digestion, Excretion. Symbiont Microorganisms and Metabolism), $1{ }^{\text {st }}$ ed; University of Tehran, Iran, 2013; pp. 85-91.

3. Force, D.C., Messenger P.S. Laboratory studies on competition among three parasites of the spotted alfalfa aphid Therioaphis maculate (Buekton). Ecology.1965, 46, 853-859.

4. Hagvar, E.B. Interspecific competition in parasitoids, with implications for biological control. Eur J Entomol. 1989, 86, $321-335$.

5. Harvey J.A. Factors affecting the evolution of development strategies in parasitoid wasps: the importance of functional constraints and incorporating complexity. Entomol Exp Appl. 2005, 117, 1-13.

6. Harvey, J.A., Poelman, E.H., Tanaka, T. Intrinsic Inter- and Intraspecific competition in endopasitoid wasps. Annu Rev Entomol, 2013, 58, 333-351.

7. McBrien H., Mackauer M. Decision to superparasitize based on larval survival: competition between aphid parasitoids Aphidius ervi and Aphidius smithi. Entomol Exp Appl. 1991, 59, 145-150.

8. Mohseni, L., Rasekh, A., Kocheli, F. Interaspecific competition between the larval instars of sexual and asexual strains of the parasitoid wasp, Lysiphlebus fabarum (Braconidae: Aphidiinae), in the simultaneous and successive ovipositions. Plant pest Res. 2017, 7(2), 53-66.

9. Outreman Y., LeRalec A., Wajnberg E., Pierre, J.S. Effects of within- and among-patch experiences on the patch-leaving decision rules in an insect parasitoid. Behav Ecol Sociobiol. 2005, 58, 208-17.

10. Radjabi, Gh. Insect ecology applied and considering the conditions of Iran. $2^{\text {nd }}$ ed.; Ministry of jihad -e- agriculture agricultural extension, education and research organization, Tehran, Iran, 2008, pp. 219-225.

11. Rasekh, A., Allahyari, H., Michaud, J.P. The effect of competition on foraging behavior of a thelytokous parasitoid, Lysiphlebus fabarum (Marshall) on Aphis fabae Scopoli. J Plant Prot 2010, 24 (3), 333-342.

12. Van Alphen J.J.M., Van Dijiken M.J., Waage J.K. A functional approach to superparasitism: host discrimination needs no be learnt. Neth J Zool. 1987, 37, 167-179.

13. Visser M.E., Van Alphen J.J.M., Nell H.W. Adaptive superparasitism and patch time allocation in solitary parasitoids: the influence of the number of parasitoids depleting the patch. Behav Ecol Sociobiol. 1990, 31, 163-171. 